\title{
Religiosity and the Spread of COVID-19: A Multinational Comparison
}

\author{
Magdalena Linke ${ }^{1}$ D $\cdot$ Konrad S. Jankowski $^{1}$
}

Accepted: 5 February 2022 / Published online: 25 February 2022

(C) The Author(s), under exclusive licence to Springer Science+Business Media, LLC, part of Springer Nature 2022

\begin{abstract}
This article considers the relationships between population religiosity and the coronavirus pandemic situation across different countries. Country-level analyses were based on data from the World Values Survey, Worldometer, and International Monetary Fund covering information about internal (beliefs) and external (practices) religiosity, religious fundamentalism, the COVID-19 pandemic, and the economic situation at two time points in 47 countries. Results showed that declared attendance at religious services is related to more COVID-19 infections and deaths, as well as when controlling for gross domestic product per capita and the number of coronavirus tests per 1 million population. This effect remained in the longitudinal perspective (of six months) and extended from external religiosity only, to both internal and external religiosity indices.
\end{abstract}

Keywords COVID-19 - Religiosity · Transmission of coronavirus

\section{Introduction}

The COVID-19 pandemic is a global health crisis causing severe human suffering and loss of life on a large scale. The crisis is testing people's capacity to respond to stressful situations not only related to health, but also to the many restrictions imposed by governments. Religiosity is considered to be a factor that helps in coping with distress, because in crisis situations people declaring faith show a tendency to turn to religion for explanation and comfort (Pajarianto et al., 2020). This association has also been observed during the COVID-19 pandemic (Bentzen, 2020; Rababa et al., 2021).

Several studies have found a positive relationship between religious involvement and physical and mental health (Brown \& Gary, 1994; Kurita et al., 2011;

Magdalena Linke

m.linke@psych.uw.edu.pl

1 Faculty of Psychology, University of Warsaw, 5/7 Stawki Street, 00-183 Warsaw, Poland 
Mahamid \& Bdier, 2021; Mullen, 1990), which is explained by such mechanisms as an increase in immune system due to lowered distress, healthier behaviors (e.g., less substance abuse), and more social support (Seybold, 2007). There are studies showing that spirituality and religiosity can help in dealing with the negative psychological effects of pandemic situation by decreasing COVID-19-related anxiety (DeRossett et al., 2021) or increasing quality of life (Cherblanc et al., 2021). It is not clear, however, whether religiosity is helpful in preventing the spread of the COVID-19 (Lee et al., 2021). Although religious people experience greater social support that can improve immunity (Uchino, 2006), a larger social network and stronger family relationships may be associated with more social contacts, which are a risk factor for contracting COVID-19. The World Health Organization, the Centers for Disease Control and Prevention, and many national health organizations state that the best way to prevent contracting the virus is to keep a physical distance from others.

Religious people may manifest a greater adherence to some pandemic restrictions because of their rule-abiding norms and altruistic tendencies (Pirutinsky et al., 2020), but, at the same time, recommendations to not participate in religious services elicit objections and may not be followed. Resistance to restrictions on participation in religious services during pandemics may be further strengthened by a lower trust in science as a social institution, which has been observed in more religious populations (Evans, 2013; Gauchat, 2012). This lower trust in science comes from a more negative view of science and scientists, accompanied by religious beliefs concerning situations (e.g., that God will save us from getting sick). Indeed, Hill et al. (2020) showed that stay-at-home orders were less followed in more religious populations in the United States.

Taking both health protective and risk factors associated with religiosity together, the question arises as to whether COVID-19 is a greater or a lesser threat in more religious populations. We assume that attendance at religious services (as well as at other gatherings) poses a risk of breaking the key restriction for COVID-19 control, namely, social distancing, and consequently we expect to find more cases and deaths caused by the pandemic in religiously active populations. Specifically, we expect that in societies where there is a greater proportion of people who are religious (believe in God, attend religious services once a week and have fundamental religious beliefs), total coronavirus cases per 1 million population and total deaths ascribed to COVID-19 per 1 million population will be greater than in societies with a lesser proportion of religious people.

\section{Materials and Methods}

\section{Religiosity}

The 47 countries $(67,917$ respondents) available in the first release of the latest World Values Survey Wave 7 (WVS-7, V1.0; Haerpfer et al., 2020) were analyzed. The survey reports data from 48 countries worldwide that were collected between mid-2017 and early-2020, but we excluded one country (Puerto Rico) because of missing data on coronavirus. Data can be access at worldvaluessurvey.org. For each 
country, a variable describing internal religiosity (the percentage of respondents who declared belief in God), a variable describing religious fundamentalism (the percentage of respondents who selected 'strongly agree' with regard to the statement 'whenever science and religion conflict, religion is always right'), and a variable describing external religiosity (the percentage of respondents who declared they attended religious services once a week) were analyzed. Table 1 presents the characteristics of the countries analyzed in the study.

\section{COVID-19}

The coronavirus data for each country were collected from the Worldometer website at two time points, on October 23, 2020, and on May 11, 2021 [https://www.world ometers.info/coronavirus/] and covered information about total coronavirus cases per 1 million population, total deaths ascribed to COVID-19 per 1 million population, and total number of coronavirus tests performed per 1 million population. The selected dates are irrelevant per se. The data from the first time point was collected when the authors decided to undertake this research topic, and the second time point a few months later was used to replicate the findings from the first time point. This was done to ensure that the observed relationships are not limited to the first time point, but rather constant and nonrandom.

\section{Economy}

The economic situation was considered a control variable. Data about the economic situation, namely gross domestic product (at purchasing power parity) per capita (international dollars) for each country, were collected from the International Monetary Fund website on October 23, 2020, and on May 11, 2021 [https://www.imf. org/external/datamapper/PPPPC@WEO].

\section{Statistical Analyses}

The Spearman's rho correlation was conducted for all variables. Then, the partial Spearman's rho correlation with two control variables, GDP per capita and number of coronavirus tests performed per 1 million population, was conducted for data from two time points. In supplemental analyses, the partial Spearman's rho correlation with other control variables potentially associated with religiosity and COVID19 deaths (namely median age, marriage rates, population density, population urbanization, and Democracy Index) was conducted. All tests were two-tailed with a $p<0.05$ threshold for statistical significance. 


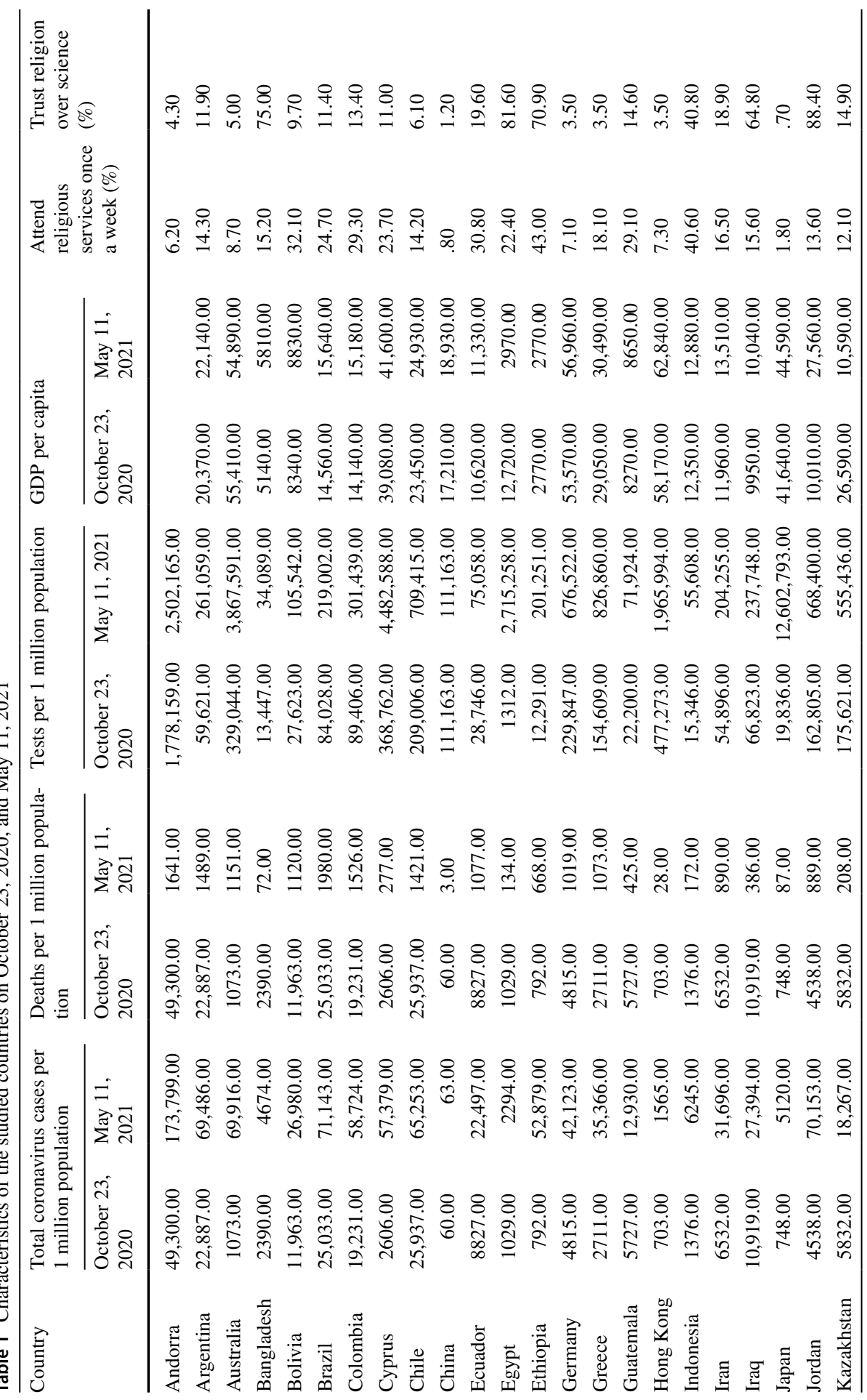




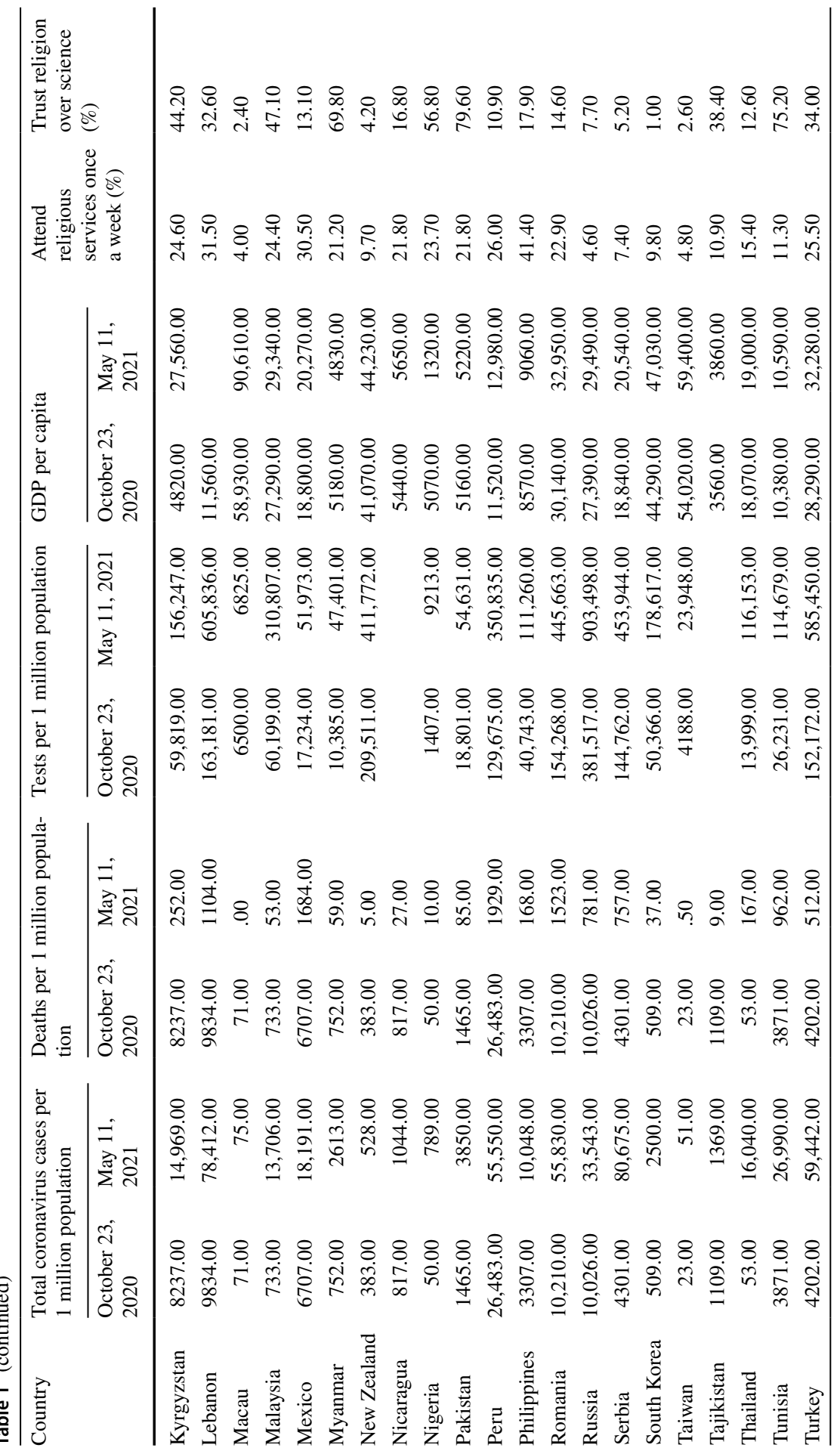




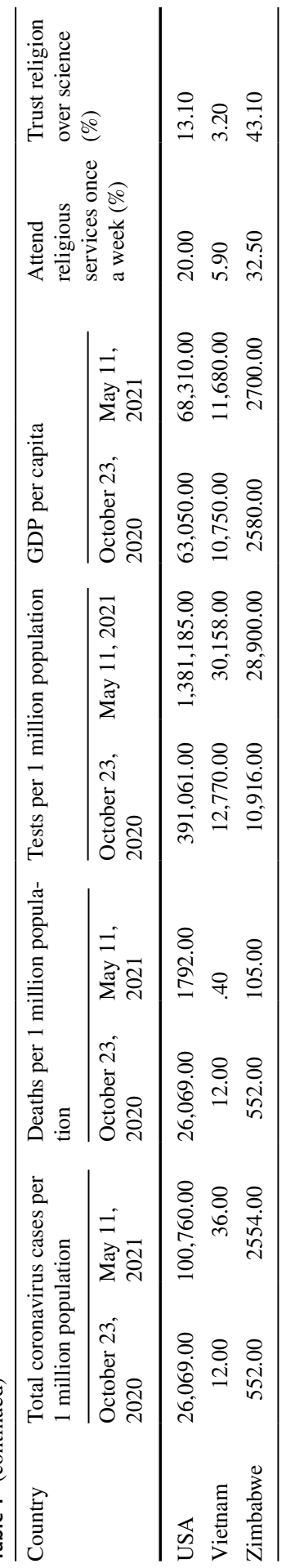




\section{Results}

At the first time point (October 23, 2020) a higher number of COVID-19 cases per 1 million population was related to declared participation in religious services (percentage of respondents who attend religious services once a week), but was unrelated to religious beliefs (percentage of respondents who declared belief in God), and religious fundamentalism (percentage of respondents who declared that whenever science and religion conflict, religion is always right). Similarly, a greater number of deaths per 1 million population was related to declared participation in religious services, but unrelated to religious beliefs (Table 2). These associations remained significant after controlling for gross domestic product per capita (GDP per capita) and for the number of COVID-19 tests conducted per 1 million population (Table 3). In a replication of analyses on data from May 11, 2021, the number of COVID-19 cases per 1 million population was unrelated to any indices of religiosity, nor to religious fundamentalism, but the greater number of deaths per 1 million population remain related to widespread participation in religious services (Table 4). However, after controlling for GDP per capita and for the number of COVID-19 tests conducted per 1 million population, the higher number of COVID19 cases per 1 million population and more deaths per 1 million population were related to both external (declared participation in religious services one a week) and internal (greater percentage of those who believe in God) religiosity (Table 5). Supplementary analyses with a set of other control variables (median age, marriage rates, population density, population urbanization, and Democracy Index) showed results that were in line with the abovementioned findings (Table 6 and 7 in Supplement 1).

Furthermore, at the first time point fewer COVID-19 tests per 1 million population were conducted in societies with widespread belief in God and trust in religion over science (Table 2), but these associations were no longer significant after controlling for GDP per capita $\left(\mathrm{rho}_{\text {partial }}=0.172 ; p=0.275 ; \mathrm{rho}_{\text {partial }}=0.0 .84 ; p=0.598\right.$ respectively). Similarly, at the second time point fewer COVID-19 tests per 1 million population were conducted in societies with widespread belief in God (Table 3), but these association was no longer significant after controlling for GDP per capita $\left(\right.$ rho $\left._{\text {partial }}=0.033 ; p=0.837\right)$.

\section{Discussion}

This study examined relationships between the COVID-19 pandemic situation and internal and external indices of religiosity, and religious fundamentalism. Data from 47 countries were analyzed in two time points, on October 23, 2020 (number of currently infected people worldwide-8,506,998; number of daily deaths-6549) and on May 11, 2021 (number of currently infected people worldwide-17,959,018; number of daily deaths-13,424). The results showed that more COVID-19 cases and deaths per 1 million population appear in countries with widespread attendance to religious services, regardless of GDP per capita and the number of conducted 


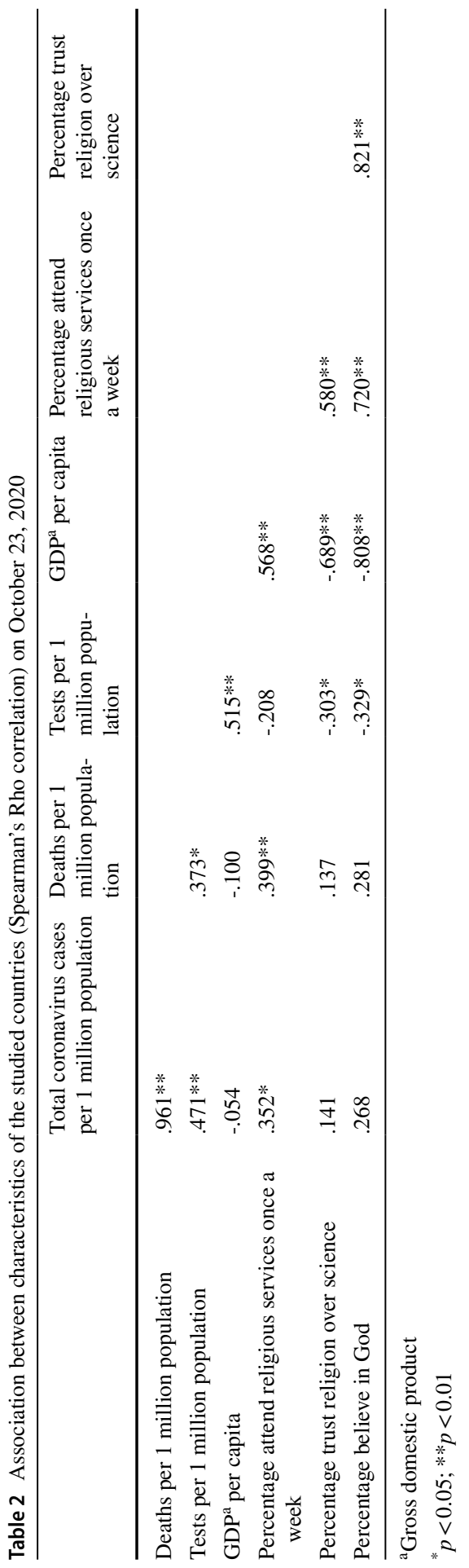




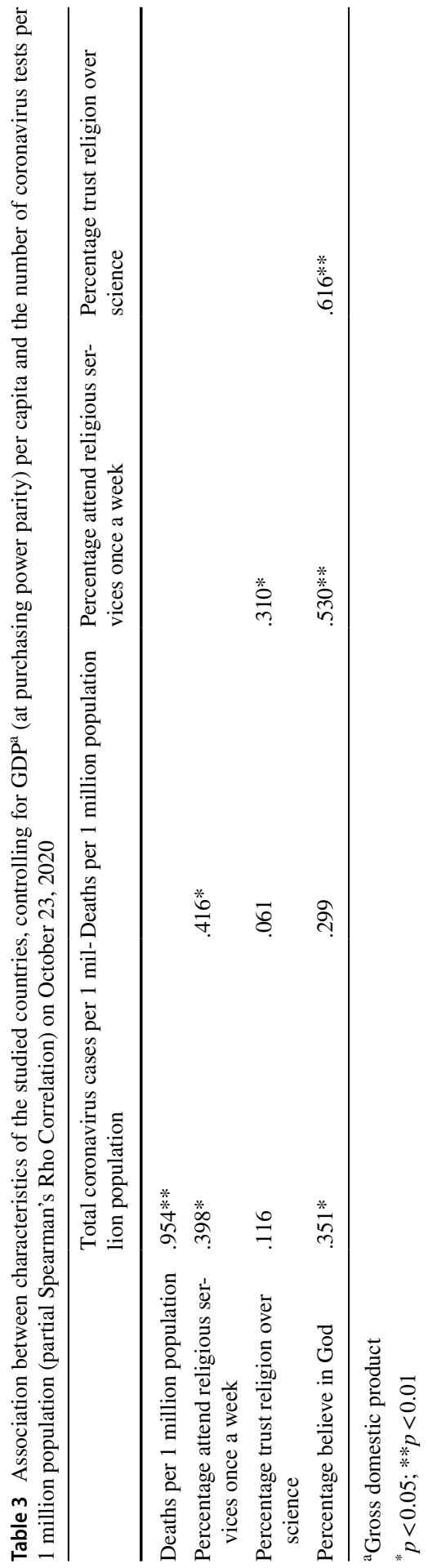




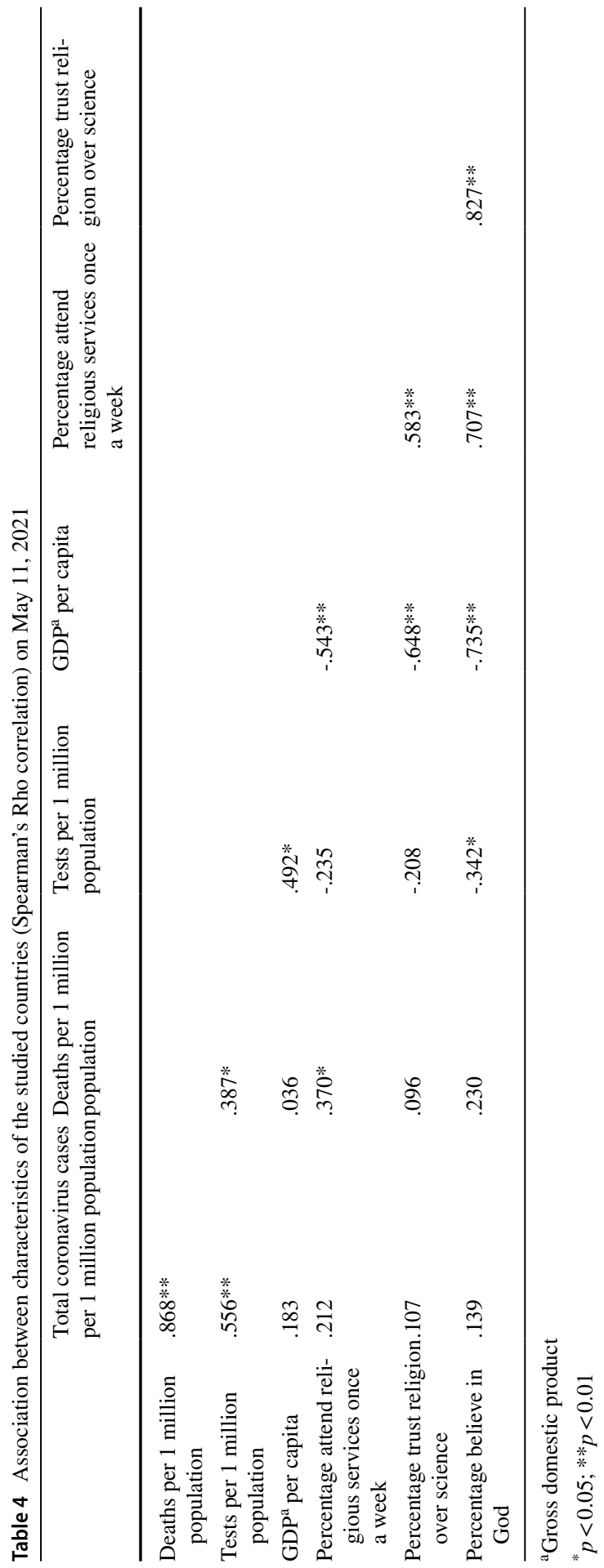




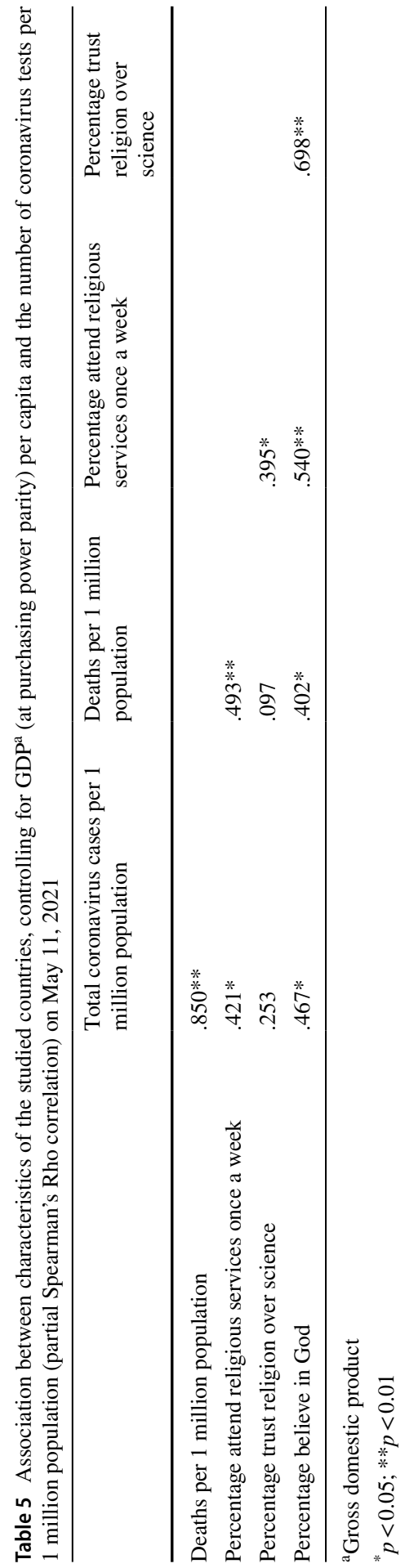


COVID-19 tests. This relationship was present in both time points. For the second time point (May 11, 2021), when the coronavirus-related statistics in the world were worse than at the first time point (October 23, 2020), both external and internal indices of religiosity were related to greater numbers of COVID-19 cases and deaths per 1 million population. The number of COVID-19 tests performed per 1 million population was lower in societies with more people trusting religion rather than science (this was true only for the first time point) and more believers-an association explained by the lower GDP per capita in these countries.

The results are of great importance for control of the COVID-19 spread. To the best of our knowledge, this is the first study showing on a global scale that in countries with more residents attending religious services, there are more coronavirus cases and more deaths caused by coronavirus. These results are in line with the outcomes of studies conducted locally (Millar et al., 2021; Vermeer \& Kregting, 2020) and observations of numerous COVID-19 cases linked to places of worship and religious gatherings (Canete, 2021; Tan et al., 2021; Yezli \& Khan, 2021). It needs to be stressed that at the first time point, internal religiosity was unrelated to the severity of the pandemic, which indicates that it is not religious belief per se contributing to the severity, but attendance at religious practices, which typically involves physical proximity to others. However, at the second time point, both external and internal religiosity were related to the severity of the pandemic, which suggests that other factors related to religiosity may also contribute to the spread of the coronavirus, e.g., the relationship between religiosity and compliance with pandemic restrictions, but this hypothesis has to be confirmed in future studies.

At the same time, we found an association between internal religiosity and religious fundamentalism and a lower number of coronavirus tests conducted per 1 million population, which is recognized as a factor hindering control of the COVID-19 pandemic. Fewer tests were conducted in countries with higher percentages of the population declaring belief in God and trust in religion over science, which is in line with studies reporting less general trust in science in religious populations (Gauchat, 2012). This suggests that in such societies testing may be considered not as important, and that both potential COVID-19 carriers and those in charge of directing them for tests are less likely to consider testing. This idea is strengthened by findings that fundamental religious beliefs are related to fewer precautionary behaviors during the COVID-19 pandemic (Perry et al., 2020) and that the religiosity is negatively related to COVID-19 vaccination intention (Olagoke et al., 2021). However, the discussed association was no longer significant after controlling for GDP per capita, lower values of which are linked to greater religiosity. This suggests the possibility of another pathway: less wealthy countries, that are simultaneously more religious, cannot afford extensive coronavirus testing. The causal mechanism cannot be confidently inferred in this study due to the observational nature of the data; both religious and economic contributors to lower testing rates are possible.

We found one preliminary report (preprint not undergone peer review) that reports a possible protective effect of religious beliefs and practices (attendance to religious services once a week) on the spread of COVID-19 and its outcome mortality (Rajkumar, 2020). However, in Rajkumar's study, COVID-19 data were collected in May 2020, when the likelihood of contracting infection was lower than 
it was in October 2020 or May 2021. It is possible that religious practices could have served as a protective factor due to their role in boosting immunity by lowering distress and increasing social support (Seybold, 2007). However, the number of infections increased dramatically and the health benefits of religious practices (e.g., communal worship) were overshadowed by their risks, as indicated by the results of our research.

Governments in many countries, in response to the COVID-19 pandemic, adopted orders to stay at home, shut down facilities, and ban some types of social gatherings. There is evidence that places of religious worship are clusters of COVID-19 spreading (Pung et al., 2020) and are regarded as gathering places characterized by high infection transmissibility (Saidan et al., 2020), yet religious services have not been prohibited in many countries. Countries that have not completely closed the places of worship for their believers have mostly introduced state COVID-19 regulations regarding worship and conduct religious rituals. However, these restrictions can be followed in various ways by believers and the authorities (e.g., Begović, 2020). This is a sensitive issue that causes social opposition among believers (for example, in the USA there were a number of legal prosecutions in response to local governments' prohibitions of religious gatherings; Brannon, 2020), who demand that authorities outline the reasons for banning services. Therefore, it is of the upmost importance to research the issue and quickly disseminate scientific knowledge about the pros and cons of communal worship.

\section{Study Limitations}

The main limitation of this study is that we rely on population data and no direct conclusions about individuals can be drawn. There is an ongoing debate in contemporary cross-cultural psychology as to whether the structure of particular variables at the individual and country level is the same, and studies show that at least in cases of values it is (e.g., Fischer et al., 2010). Secondly, causal interpretations should be drawn with caution, because this was an observational study, not the experimental one (Concato, 2004). While experimental study design can allow for obtaining evidence for causality, it can be rarely applied to research risk factors of diseases. Therefore, observational studies, such as the one that we have conducted, can be a valuable source of information indicating potential mechanisms that need further verification (Hill, 1965). The third limitation is that in this study we do not consider cross-cultural differences in people's behavior at places of worship, information about the long-term pandemic control strategies used by national governments or other possible factors that could influence the results on a particular day. However, the analysis of the data from the second time point showed similar results, which suggests that the observed relationships are constant and not only related to a specific day. The fourth limitation stems from the fact that we relied on secondary data which limited the countries under investigation to those that were covered by available databases. As a result, due to the unavailability of data, some secularized countries with high morbidity rates were not included in our analyses (e.g., France, the Netherlands or the Czech Republic). Meanwhile, many countries with high levels of 
religiosity were those with presumably poorer healthcare systems - the confounding factor that we partly controlled for in analyses by including GDP and the number of coronavirus tests conducted per 1 million population (Raghupathi \& Raghupathi, 2020).

It should be also taken into account that COVID-19 mortality risk is possibly a result of multiple sociodemographic and geographic determinants and future studies should consider them, as in our study only a few such variables were controlled for. Nevertheless, existing data show that adherence to certain religious groups remains a significant factor in COVID-19 mortality rates even after controlling for such variables (Gaughan et al., 2021). One should also keep in mind that there can exist different methodologies in various countries used to measure the number of deaths caused by the pandemic. One more limitation of the study stems from the timing of the religiosity measurement conducted within the World Values 7 survey. Specifically, the World Values 7 survey referred mainly to the pre-pandemic period (up to early 2020) and we assumed that physical participation in religious services in various countries during COVID-19 pandemic was proportional to the pre-pandemic levels. This, however, could have been affected by various factors, such as access to online religious services, which we partly controlled in analyses by including GDP (a positive association between GDP and internet penetration; Xiaoming \& Kay, 2004).

Supplementary Information The online version contains supplementary material available at https://doi. org/10.1007/s10943-022-01521-9.

Funding This work was supported by grants from the University of Warsaw.

Availability of data and material All data sources are described in the manuscript.

\section{Declarations}

Conflict of interest The authors declare that they have no conflict of interest.

\section{References}

Begović, N. (2020). Restrictions on religions due to the COVID-19 pandemic. Responses of religious communities in Bosnia and Herzegovina. Journal of Law, Religion and State, 8(2-3), 228-250. https://doi.org/10.1163/22124810-2020007.

Bentzen, J. (2020). In crisis, we pray: Religiosity and the COVID-19 pandemic. CEPR Discussion Paper. Journal of Economic Behavior and Organization, 92, 541-583. https://doi.org/10.1016/j.jebo.2021. 10.014

Brannon, V. C. (2020). Banning religious assemblies to stop the spread of COVID-19. Congressional Research Service, 2020 June. Report No.: LSB10450, Version 2. https://pesquisa.bvsalud.org/ global-literature-on-novel-coronavirus-2019-ncov/resource/pt/grc-739758?lang=en

Brown, D. R., \& Gary, L. E. (1994). Religious involvement and health status among African-American males. Journal of the National Medical Association, 86(11), 825-831.

Canete, J. J. O. (2021). When expressions of faith in the Philippines becomes a potential COVID-19 'superspreader.' Journal of Public Health (oxford), 43(2), e366-e367. https://doi.org/10.1093/pub$\mathrm{med} / \mathrm{fdab082}$ 
Cherblanc, J., Bergeron-Leclerc, C., Maltais, D., Cadell, S., Gauthier, G., Labra, O., \& Ouellet-Plamondon, C. (2021). Predictive factors of spiritual quality of life during the COVID-19 pandemic: A multivariate analysis. Journal of Religion and Health, 60(3), 1475-1493. https://doi.org/10.1007/ s10943-021-01233-6

Concato, J. (2004). Observational versus experimental studies: What's the evidence for a hierarchy? Neurotherapeutics, 1(3), 341-347. https://doi.org/10.1602/neurorx.1.3.341

DeRossett, T., LaVoie, D. J., \& Brooks, D. (2021). Religious coping amidst a pandemic: Impact on COVID-19-related anxiety. Journal of Religion and Health, 60(5), 3161-3176. https://doi.org/10. $1007 / \mathrm{s} 10943-021-01385-5$

Evans, J. H. (2013). The growing social and moral conflict between conservative Protestantism and science. Journal for the Scientific Study of Religion, 52(2), 368-385. https://doi.org/10.1111/jssr.12022

Fischer, R., Vauclair, C.-M., Fontaine, J. R. J., \& Schwartz, S. H. (2010). Are individual-level and country-level value structure different? Testing Hofstede's legacy with the Schwartz Values Survey. Journal of Cross-Cultural Psychology, 41(2), 135-151. https://doi.org/10.1177/0022022109 354377

Gauchat, G. (2012). Politicization of science in the public sphere: A study of public trust in the United States, 1974 to 2010. American Sociological Review, 77(2), 167-187. https://doi.org/10.1177/ 0003122412438225

Gaughan, C. H., Ayoubkhani, D., Nafilyan, V., Goldblatt, P., White, C., Tlngay, K., \& Bannister, N. (2021). Religious affiliation and COVID-19-related mortality: A retrospective cohort study of prelockdown and postlockdown risks in England and Wales. Journal of Epidemiology and Community Health, 75, 509-514. https://doi.org/10.1136/jech-2020-215694

Haerpfer, C., Inglehart, R., Moreno, A., Welzel, C., Kizilova, K., Diez-Medrano, J., Abdel-Latif, A.-H., Acuña, O. M., Al Braizat, F., Alekseeva, T., Almakaeva, A., Aragón Trelles, J., Auh, S. Y., Bakaloff, Y., Batalla Salvadó, P., Ben Hafaiedh, A., Biolcati, F., Bomhoff, E. J., Botagoz, R., Bureekul, T., et al. (2020). World Values Survey: Round Seven-Country-Pooled Datafile. Madrid, Spain \& Vienna, Austria: JD Systems Institute \& WVSA Secretariat [Retrieved 23 October 2020]. Available from: http://www.worldvaluessurvey.org/WVSDocumentationWV7.jsp\#

Hill, B. A. (1965). The environment and disease association or causation? Proceedings of the Royal Society of Medicine, 58(5), 295-300.

Hill, T. D., Gonzalez, K., \& Burdette, A. M. (2020). The blood of Christ compels them: State religiosity and state population mobility during the coronavirus (COVID-19) pandemic. Journal of Religion and Health, 59(5), 2229-2242. https://doi.org/10.1007/s10943-020-01058-9

Kurita, A., Takase, B., Shinagawa, N., Kodani, E., Okada, K., Iwahara, S., Kusama, Y., \& Atarashi, H. (2011). Spiritual activation in very elderly individuals assessed as heart rate variability and plasma IL/10/IL-6 ratios. International Heart Journal, 52(5), 299-303. https://doi.org/10.1536/ ihj.52.299

Lee, M., Lim, H., Xavier, M. S., \& Lee, E. Y. (2021). 'A divine infection': A systematic review on the roles of religious communities during the early stage of COVID-19. Journal of Religion and Health. https://doi.org/10.1007/s10943-021-01364-w

Mahamid, F. A., \& Bdier, D. (2021). The association between positive religious coping, perceived stress, and depressive symptoms during the spread of coronavirus (COVID-19) among a sample of adults in Palestine: Across sectional study. Journal of Religion and Health, 60(1), 34-49. https://doi.org/ 10.1007/s10943-020-01121-5

Millar, J. A., Dao, H. D. N., Stefopulos, M. E., Estevam, C. G., Fagan-Garcia, K., Taft, D. H., Park, C., Alruwaily, A., Desai, A. N., \& Majumder, M. S. (2021). Risk factors for increased COVID-19 case-fatality in the United States: A county-level analysis during the first wave. PLoS ONE, 16(10), e0258308. https://doi.org/10.1371/journal.pone.0258308

Mullen, K. (1990). Religion and health: A review of the literature. International Journal of Sociology and Social Policy, 10(1), 85-96. https://doi.org/10.1108/eb013088

Olagoke, A. A., Olagoke, O. O., \& Hughes, A. M. (2021). Intention to vaccinate against the novel 2019 coronavirus disease: The role of health locus of control and religiosity. Journal of Religion and Health, 60(1), 65-80. https://doi.org/10.1007/s10943-020-01090-9

Pajarianto, H., Kadir, A., Galugu, N., Sari, P., \& Februantj, S. (2020). Study from home in the middle of the COVID-19 pandemic: Analysis of religiosity, teacher, and parents support against academic stress. Talent Development \& Excellence, 12(2s), 1791-1807. 
Perry, S. L., Whitehead, A. L., \& Grubbs, J. B. (2020). Culture wars and COVID-19: Christian nationalism, religiosity, and Americans' behavior during the coronavirus pandemic. Journal for the Scientific Study of Religion, 59(3), 405-416. https://doi.org/10.1111/jssr.12677

Pirutinsky, S., Cherniak, A. D., \& Rosmarin, A. D. H. (2020). COVID-19, mental health, and religious coping among American Orthodox Jews. Journal of Religion and Health, 59(5), 2288-2301. https:// doi.org/10.1007/s10943-020-01070-Z

Pung, R., Chiew, C. J., Young, B.E., Chin, S., I-C Chen, M., Clapham, H. E., Cook, A. R., MaurerStroh, S., Toh, M. P. H. S., Poh, C., Low, M., Lum, J., Koh, V. T. J., Mak, T. M., Cui, L., Lin, R. V. T. P., Heng, D., Leo, P. Y.-S., Lye, D. C., \& Lee, V. J. M. (2020). Investigation of the three clusters of COVID-19 in Singapore: Implications for surveillance and response measures. The Lancet, 395(10229), 1039-1046. https://doi.org/10.1016/S0140-6736(20)30528-6.

Rababa, M., Hayajneh, A. A., \& Bani-Iss, W. (2021). Association of death anxiety with spiritual wellbeing and religious coping in older adults during the COVID-19 pandemic. Journal of Religion \& Health, 60(1), 50-63. https://doi.org/10.1007/s10943-020-01129-x

Raghupathi, V., \& Raghupathi, W. (2020). Healthcare expenditure and economic performance: Insights from the United States Data. Frontiers in Public Health, 8, 156. https://doi.org/10.3389/fpubh.2020. 00156

Rajkumar, R. P. (2020). The relationship between measures of religiosity and the prevalence and outcome of COVID-19: A population-level pilot study. [Preprint]. [cited Oct 27, 2020]. Available from: https://www.researchsquare.com/article/rs-33245/v.

Saidan, M. N., Shbool, M. A., Arabeyyat, O. S., Al-Shihabi, S. T., Abdallat, Y. A., Barghash, M. A., \& Saidan, H. (2020). Estimation of the probable outbreak size of novel coronavirus (COVID-19) in social gathering events and industrial activities. International Journal of Infectious Diseases, 98, 321-327. https://doi.org/10.1016/j.ijid.2020.06.105

Seybold, K. S. (2007). Physiological mechanisms involved in religiosity/ spirituality and health. Journal of Behavioral Medicine, 30(4), 303-309. https://doi.org/10.1007/s10865-007-9115-6

Tan, M. M., Musa, A. F., \& Su, T. T. (2021). The role of religion in mitigating the COVID-19 pandemic: The Malaysian multi-faith perspectives. Health Promotion International, daab041. Advance online publication. https://doi.org/10.1093/heapro/daab041.

Uchino, B. N. (2006). Social support and health: A review of physiological processes potentially underlying links to disease outcomes. Journal of Behavioral Medicine, 29(4), 377-387. https://doi.org/10. 1007/s10865-006-9056-5

Vermeer, P., \& Kregting, J. (2020). Religion and the transmission of COVID-19 in the Netherlands. Religions, 11(8), 393. https://doi.org/10.3390/rel11080393

Xiaoming, H., \& Kay, C. S. (2004). Factors affecting internet development: An Asian survey. First Monday, 9(2). https://firstmonday.org/ojs/index.php/fm/article/view/1118/1038

Yezli, S., \& Khan, A. (2021). COVID-19 pandemic: It is time to temporarily close places of worship and to suspend religious gatherings. Journal of Travel Medicine, 28(2), taaa065. https://doi.org/10.1093/ $\mathrm{jtm} / \mathrm{taaa} 065$

Publisher's Note Springer Nature remains neutral with regard to jurisdictional claims in published maps and institutional affiliations. 